\title{
Common fixed point theorems for generalized contractive mappings with applications
}

Nawab Hussain ${ }^{1}$, Masood Hussain Shah², Alireza Amini-Harandi ${ }^{3}$ and Zahid Akhtar ${ }^{{ }^{*}}$

\section{"Correspondence:}

zahid_9896@yahoo.com

${ }^{4}$ Department of Mathematics, The

Islamia University of Bahawalpur,

Bahawalpur, 63100, Pakistan

Full list of author information is

available at the end of the article

\begin{abstract}
Certain common fixed point results involving four mappings satisfying generalized contractive conditions on a cone metric type space are obtained. Our results substantially improve and extend a number of known results. An example is given in support of the new results developed here. As an application, we establish the existence of a solution for an implicit integral equation.
\end{abstract}

MSC: Primary 47H09; 47H10; secondary 49M05

Keywords: cone metric type space; coincidence point; common fixed point; generalized contractive mapping; nonexpansive mapping

\section{Introduction}

The Banach contraction principle is a remarkable result in the metric fixed point theory. Over the years, it has been generalized in different directions and spaces by several mathematicians (see [1-44]). In 1972, Zamfirescu [44] defined Z-operators on metric spaces: There exist real numbers $a, b$ and $c$ satisfying $0<a<1,0<b, c<\frac{1}{2}$ such that for each $x, y \in X$, one of the following holds:

$\left(\mathrm{Z}_{1}\right) d(T x, T y) \leq a d(x, y)$;

$\left(\mathrm{Z}_{2}\right) d(T x, T y) \leq b[d(x, T x)+d(y, T y)]$

$\left(\mathrm{Z}_{3}\right) d(T x, T y) \leq c[d(x, T y)+d(y, T x)]$.

In 1974, Ćirić [11] defined quasi-contraction $\left(C^{q}\right)$ if for some $0 \leq h<1$ and all $x, y \in X$,

$$
d(T x, T y) \leq h \max \{d(x, y), d(x, T x), d(y, T y), d(x, T y), d(y, T x)\} .
$$

Clearly, the Zamfirescu operator is quasi-contractive.

In 1983, Naimpally and Singh [33] defined a generalized contractive operator as follows:

$$
d(T x, T y) \leq h \max \{d(x, y), d(x, T x), d(y, T y), d(x, T y)+d(y, T x)\}
$$

for some $0 \leq h<1$ and for all $x, y \in X$.

A generalized contractive operator in (1.2) is more general than quasi-contraction.

In $[25,29]$ the authors investigated quasi-contractions on cone metric spaces and obtained fixed point theorems for such mappings under a different condition. Recently 
Cvetković et al. [14] and Hussain and Shah [22] introduced the notion of a cone metric type space, which is a generalization of a cone metric space, and proved some common fixed point theorems and KKM-mappings results respectively.

In this paper we consider mappings on a cone metric type space (CMTS) with a solid cone. We prove new common fixed point theorems involving four mappings satisfying a generalized contractive and a generalized nonexpansive conditions. Our results are generalization of theorems proved in $[14,19,27,40,43]$ and some other authors. Almost all of our results are proved without the assumption of the continuity of mappings.

The paper is organized as follows. In Section 2 we review some definitions and wellknown results which will be needed in the sequel. In Section 3 and 4 we prove the existence of common fixed points of four mappings. We also present some corollaries which establish the fact that our results are generalization of several recent results in the literature. In Section 5, we present an application to integral equations to illustrate the usability of the obtained results.

\section{Definitions and notation}

Let $E$ be a real Banach space and $P$ a subset of $E$. We use the symbol 0 to denote the zero element of $E$ and the symbol int $P$ to denote the interior of $P$. The subset $P$ is called a cone if and only if:

(I) $P$ is closed, nonempty and $P \neq\{0\}$;

(II) $a, b \in \mathbb{R}, a, b \geq 0$, and $x, y \in P$ such that $a x+b y \in P$;

(III) $P \cap(-P)=\{0\}$.

For a given cone $P$, a partial ordering $\leq$ with respect to $P$ is introduced as follows: $x \leq y$ if and only if $y-x \in P ; x<y$ means $x \leq y$ but $x \neq y$; if $y-x \in \operatorname{int} P$, one writes $x \ll y$; if $\operatorname{int} P \neq \emptyset$, the cone $P$ is called a solid cone.

In this paper we always suppose that $E$ is a real Banach space, $P \subseteq E$ is a solid cone and $\leq$ is partial ordering with respect to $P$.

Definition 2.1 Let $X$ be a nonempty set and $E$ be a real Banach space with a cone $P$. A vector-valued function $d: X \times X \rightarrow E$ is said to be a cone metric type function on $X$ with the constant $k \geq 1$ if:

$\left(\mathrm{d}_{1}\right) 0 \leq d(x, y)$ for all $x, y \in X$ and $d(x, y)=0$ if and only if $x=y$;

$\left(\mathrm{d}_{2}\right) d(x, y)=d(y, x)$ for all $x, y \in X$;

$\left(\mathrm{d}_{3}\right) d(x, y) \leq k[d(x, z)+d(z, y)]$ for all $x, y, z \in X$.

The pair $(X, d)$ is called a cone metric type space (CMTS).

Remark 2.2 For $k=1$, the above definition of CMTS reduces to that of a cone metric space introduced in [19].

Definition 2.3 Let $(X, d)$ be a CMTS and $\left\{x_{n}\right\}$ be a sequence in $X$ :

(I) $\left\{x_{n}\right\}$ converges to $x$ if for every $c \in E$ with $0 \ll c$ there exists $n_{0} \in \mathbb{N}$ such that $d\left(x_{n}, x\right) \ll c$ for all $n>n_{0}$. We write $\lim _{n \rightarrow \infty} x_{n}=x$, or $x_{n} \rightarrow x$ as $n \rightarrow \infty$.

(II) If for every $c \in E$ with $0 \ll c$ there exists $n_{0} \in \mathbb{N}$ such that $d\left(x_{n}, x_{m}\right) \ll c$ for all $n, m>n_{0}$, then $\left\{x_{n}\right\}$ is called a Cauchy sequence in $X$.

(III) If every Cauchy sequence is convergent in $X$, then $X$ is called a complete CMTS. 
Let $E$ be an ordered real Banach space with a cone $P$. The following properties hold $(a, b, c \in E)$ :

$\left(\mathrm{C}_{1}\right)$ If $a \leq b$ and $b \ll c$, then $a \ll c$;

$\left(\mathrm{C}_{2}\right)$ If $0 \leq a \ll c$ for all $c \in \operatorname{int} P$, then $a=0$;

$\left(C_{3}\right)$ If $a \leq \lambda a$, where $a \in P$ and $0 \leq \lambda<1$, then $a=0$;

$\left(\mathrm{C}_{4}\right)$ Let $x_{n} \rightarrow 0$ in $E$ and $0 \ll c$.

Then there exists a positive integer $n_{0}$ such that $x_{n} \ll c$ for each $n>n_{0}$.

Definition 2.4 Let $F, G: X \rightarrow X$ be mappings on a set $X$ :

(i) If $y=F x=G x$ for some $x \in X$, then $x$ is called a coincidence point of $F$ and $G$, and $y$ is called a point of coincidence of $F$ and $G$;

(ii) The pair $\{F, G\}$ is called weakly compatible if $F$ and $G$ commute at all of their coincidence points, that is, $F G x=G F x$ for all $x \in C(F, G)=\{x \in X: F x=G x\}$.

(iii) The pair $\{F, G\}$ is called occasionally weakly compatible (in brief OWC) [28] if $F G x=G F x$ for some $x \in C(F, G)$.

\section{Generalized contractive operators}

First we show the existence of a unique fixed point.

Theorem 3.1 Let $(X, d)$ be a cone metric type space with the constant $k \geq 1$ and let $P$ be a solid cone. Let $T: X \rightarrow X$ be a mapping satisfying the contractive condition

$$
d(T x, T y) \leq \frac{\lambda}{k} m(x, y)
$$

where

$$
m(x, y) \in k\{d(x, y), d(x, T x)+d(y, T y), d(x, T y)+d(y, T x)\}
$$

for all $x, y \in X$ and for some constant $\lambda \in\left(0, \frac{1}{k+k^{2}}\right)$. If $T X$ is complete, then $T$ has a unique fixed point in $X$.

Proof For $x_{0} \in X$, we construct a sequence $\left\{x_{n}\right\}$ in $X$ by

$$
x_{n+1}=T x_{n} \quad \text { for } n \geq 0 .
$$

We show that $\left\{x_{n}\right\}$ is a Cauchy sequence in $X$. For $n \geq 1$, we have

$$
d\left(x_{n+1}, x_{n}\right)=d\left(T x_{n}, T x_{n-1}\right) \leq \frac{\lambda}{k} m\left(x_{n}, x_{n-1}\right),
$$

where

$$
\begin{aligned}
m\left(x_{n}, x_{n-1}\right) & \in k\left\{d\left(x_{n}, x_{n-1}\right), d\left(x_{n}, T x_{n}\right)+d\left(x_{n-1}, T x_{n-1}\right), d\left(x_{n}, T x_{n-1}\right)+d\left(x_{n-1}, T x_{n}\right)\right\} \\
& =k\left\{d\left(x_{n}, x_{n-1}\right), d\left(x_{n}, x_{n+1}\right)+d\left(x_{n-1}, x_{n}\right), d\left(x_{n}, x_{n}\right)+d\left(x_{n-1}, x_{n+1}\right)\right\} \\
& =k\left\{d\left(x_{n}, x_{n-1}\right), d\left(x_{n}, x_{n+1}\right)+d\left(x_{n-1}, x_{n}\right), d\left(x_{n-1}, x_{n+1}\right)\right\} .
\end{aligned}
$$

Thus we have the following three cases: 
(i) $d\left(x_{n+1}, x_{n}\right) \leq \lambda d\left(x_{n}, x_{n-1}\right)$;

(ii) $d\left(x_{n+1}, x_{n}\right) \leq \lambda\left[d\left(x_{n}, x_{n+1}\right)+d\left(x_{n-1}, x_{n}\right)\right] \leq\left(\frac{\lambda}{1-\lambda}\right) d\left(x_{n-1}, x_{n}\right)$;

(iii) $d\left(x_{n+1}, x_{n}\right) \leq \lambda d\left(x_{n-1}, x_{n+1}\right) \leq \lambda k\left[d\left(x_{n-1}, x_{n}\right)+d\left(x_{n}, x_{n+1}\right)\right] \leq\left(\frac{\lambda k}{1-\lambda k}\right) d\left(x_{n-1}, x_{n}\right)$.

Let $\alpha=\max \left\{\lambda, \frac{\lambda}{1-\lambda}, \frac{\lambda k}{1-\lambda k}\right\}$. Then $\alpha=\max \left\{\lambda, \frac{\lambda}{1-\lambda}, \frac{k \lambda}{1-k \lambda}\right\}=\frac{k \lambda}{1-k \lambda}$ and so $k \alpha<1$ if and only if $\frac{k^{2} \lambda}{1-k \lambda}<1$ if and only if $\lambda \in\left(0, \frac{1}{k+k^{2}}\right)$.

Thus

$$
d\left(x_{n+1}, x_{n}\right) \leq \alpha d\left(x_{n-1}, x_{n}\right) \leq \cdots \leq \alpha^{n} d\left(x_{1}, x_{0}\right)
$$

Since $k \geq 1$, for $m>n$, we have

$$
\begin{aligned}
d\left(x_{n}, x_{m}\right) & \leq k d\left(x_{n}, x_{n+1}\right)+k^{2} d\left(x_{n+1}, x_{n+2}\right)+\cdots+k^{m-n-1} d\left(x_{m-1}, x_{m}\right) \\
& \leq\left(k \alpha^{n}+k^{2} \alpha^{n+1}+\cdots+k^{m-n-1} \alpha^{m-1}\right) d\left(x_{1}, x_{0}\right) \\
& \leq\left(\frac{k}{1-k \alpha}\right) \alpha^{n} d\left(x_{1}, x_{0}\right) \rightarrow 0 \quad \text { as } n \rightarrow \infty
\end{aligned}
$$

Now, by $\left(C_{4}\right)$ and $\left(C_{1}\right)$, it follows that for every $c \in$ int $P$, there exists a positive integer $n_{0}$ such that $d\left(x_{n}, x_{m}\right) \ll c$ for every $m>n>n_{0}$, so $\left\{x_{n}\right\}$ is a Cauchy sequence. Since $T X$ is a complete subspace of $X$, there exists $p \in T X$ such that $\lim _{n \rightarrow \infty} x_{n}=p=\lim _{n \rightarrow \infty} T x_{n}$. We show that $p$ is a fixed point of $T$. Consider

$$
\begin{aligned}
d(p, T p) & \leq k\left(d\left(p, x_{n+1}\right)+d\left(x_{n+1}, T p\right)\right)=k d\left(p, x_{n+1}\right)+k d\left(T x_{n}, T p\right) \\
& \leq k d\left(p, x_{n+1}\right)+k \frac{\lambda}{k} m\left(x_{n}, p\right),
\end{aligned}
$$

where

$$
m\left(x_{n}, p\right) \in k\left\{d\left(x_{n}, p\right), d\left(x_{n}, x_{n+1}\right)+d(p, T p), d\left(x_{n}, T p\right)+d\left(p, x_{n+1}\right)\right\} .
$$

Let $0 \ll c$. Then at least one of the following three cases holds:

1.

$$
d(p, T p) \leq k d\left(p, x_{n+1}\right)+\lambda k d\left(x_{n}, p\right) \ll k \frac{c}{2 k}+\lambda k \frac{c}{2 \lambda k}=c,
$$

whenever $n \geq K_{1}$.

2 .

$$
d(p, T p) \leq k d\left(p, x_{n+1}\right)+\lambda k d\left(x_{n}, x_{n+1}\right)+\lambda k d(p, T p)
$$

implies

$$
\begin{aligned}
d(p, T p) & \leq \frac{k}{1-\lambda k} d\left(p, x_{n+1}\right)+\frac{\lambda k}{1-\lambda k} d\left(x_{n}, x_{n+1}\right) \\
& \ll \frac{k}{1-\lambda k} \frac{1-\lambda k}{2 k} c+\frac{\lambda k}{1-\lambda k} \frac{1-\lambda k}{2 \lambda k} c \\
& =c,
\end{aligned}
$$

whenever $n \geq K_{2}$. 
3.

$$
\begin{aligned}
d(p, T p) & \leq k d\left(p, x_{n+1}\right)+\lambda k d\left(x_{n}, T p\right)+\lambda k d\left(p, x_{n+1}\right) \\
& =k d\left(p, x_{n+1}\right)+\lambda k d\left(p, x_{n+1}\right)+\lambda k d\left(x_{n}, T p\right) \\
& \leq k d\left(p, x_{n+1}\right)+\lambda k d\left(p, x_{n+1}\right)+\lambda k^{2} d\left(x_{n}, p\right)+\lambda k^{2} d(p, T p)
\end{aligned}
$$

or

$$
\begin{aligned}
d(p, T p) & \leq \frac{k}{1-\lambda k^{2}} d\left(p, x_{n+1}\right)+\frac{\lambda k}{1-\lambda k^{2}} d\left(p, x_{n+1}\right)+\frac{\lambda k^{2}}{1-\lambda k^{2}} d\left(x_{n}, p\right) \\
& \ll \frac{k+\lambda k}{1-\lambda k^{2}} \frac{1-\lambda k^{2}}{2(k+\lambda k)} c+\frac{\lambda k^{2}}{1-\lambda k^{2}} \frac{1-\lambda k^{2}}{2 \lambda k^{2}} c \\
& =c
\end{aligned}
$$

whenever $n \geq K_{3}$.

Hence, for $n \geq \max \left\{K_{1}, K_{2}, K_{3}\right\}, d(p, T p) \leq c$.

Thus $T p=p$. Suppose that there exists $q \in X$ such that $T q=q$; then from (3.1), we have

$$
d(p, q)=d(T p, T q) \leq \frac{\lambda}{k} m(p, q),
$$

where

$$
m(p, q) \in k\{d(p, q), d(p, T p)+d(q, T q), d(p, T q)+d(q, T p)\}=k\{d(p, q), 2 d(p, q)\} .
$$

Thus we have the following two cases:

(i) $d(p, q)=d(T p, T q) \leq \lambda d(p, q)$, and

(ii) $d(T p, T q) \leq 2 \lambda d(p, q)$.

Since $\lambda \in\left(0, \frac{1}{k+k^{2}}\right)$, from both the cases we get $p=q$.

Remark 3.2 In Theorem 3.1 we have generalized and unified the fixed point theorems of Huang and Zhang [19] and corresponding results in [40].

Now we present some new common fixed point theorems involving four mappings defined on a cone metric type space.

Theorem 3.3 Let $(X, d)$ be a cone metric type space with the constant $k \geq 1$ and let $P$ be $a$ solid cone. Suppose that the self-mappings $F, G, S, T: X \rightarrow X$ are such that $S X \subset G X$ and $T X \subset F X$. Let $x_{0} \in X$, let the sequences $\left\{x_{n}\right\}$ and $\left\{z_{n}\right\}$ be defined by $z_{2 n}=G x_{2 n+1}=S x_{2 n}$ and $z_{2 n+1}=F x_{2 n+2}=T x_{2 n+1}$ for $n \geq 0$ and let $\mathcal{O}\left(x_{0}\right)=\left\{z_{n}: n \geq 0\right\}$. Assume that there exists $x_{0} \in X$ such that for some constant $\lambda \in\left(0, \frac{1}{k+k^{2}}\right)$,

$$
d(S x, T y) \leq \frac{\lambda}{k} m(x, y)
$$

where

$$
m(x, y) \in k\{d(F x, G y), d(F x, S x)+d(G y, T y), d(F x, T y)+d(S x, G y)\}
$$


for all $x, y \in F^{-1}\left\{\overline{\mathcal{O}\left(x_{0}\right)}\right\} \cup G^{-1}\left\{\overline{\mathcal{O}\left(x_{0}\right)}\right\}$. If one of $S X, T X, F X$, or $G X$ is a complete subspace of $X$, then $\{S, F\}$ and $\{T, G\}$ have a point of coincidence in $X$.

Proof We consider two cases of an odd integer $n$ and of an even $n$. For $n=2 l+1, l \in \mathbb{N}$, we have $d\left(z_{2 l+1}, z_{2 l+2}\right)=d\left(S x_{2 l+2}, T x_{2 l+1}\right)$, and from (3.2) there exists some

$$
\begin{aligned}
& m\left(x_{2 l+2}, x_{2 l+1}\right) \\
& \in k\left\{d\left(F x_{2 l+2}, G x_{2 l+1}\right), d\left(F x_{2 l+2}, S x_{2 l+2}\right)+d\left(G x_{2 l+1}, T x_{2 l+1}\right),\right. \\
&\left.d\left(F x_{2 l+2}, T x_{2 l+1}\right)+d\left(S x_{2 l+2}, G x_{2 l+1}\right)\right\} \\
&= k\left\{d\left(z_{2 l+1}, z_{2 l}\right), d\left(z_{2 l+1}, z_{2 l+2}\right)+d\left(z_{2 l}, z_{2 l+1}\right), d\left(z_{2 l+2}, z_{2 l}\right)\right\}
\end{aligned}
$$

such that

$$
d\left(z_{2 l+1}, z_{2 l+2}\right)=d\left(S x_{2 l+2}, T x_{2 l+1}\right) \leq\left(\frac{\lambda}{k}\right) m\left(x_{2 l+2}, x_{2 l+1}\right) .
$$

Thus we have the following three cases:

(i) $d\left(z_{2 l+1}, z_{2 l+2}\right) \leq \lambda d\left(z_{2 l+1}, z_{2 l}\right)$;

(ii) $d\left(z_{2 l+1}, z_{2 l+2}\right) \leq \lambda d\left(z_{2 l+1}, z_{2 l+2}\right)+d\left(z_{2 l}, z_{2 l+1}\right) \leq\left(\frac{\lambda}{1-\lambda}\right) d\left(z_{2 l+1}, z_{2 l}\right)$;

(iii) $d\left(z_{2 l+1}, z_{2 l+2}\right) \leq \lambda d\left(z_{2 l+2}, z_{2 l}\right) \leq \lambda k\left[d\left(z_{2 l+2}, z_{2 l+1}\right)+d\left(z_{2 l+1}, z_{2 l}\right)\right] \leq\left(\frac{\lambda k}{1-\lambda k}\right) d\left(z_{2 l+1}, z_{2 l}\right)$.

Let $\alpha=\max \left\{\lambda, \frac{\lambda}{1-\lambda}, \frac{\lambda k}{1-\lambda k}\right\}$. It is easy to see that $\alpha, k \alpha \in(0,1)$, such that

$$
d\left(z_{n+1}, z_{n}\right) \leq \alpha d\left(z_{n}, z_{n-1}\right), \quad n \geq 1
$$

For $n=2 l, l \in \mathbb{N}$, we have

$$
d\left(z_{2 l}, z_{2 l+1}\right)=d\left(S x_{2 l}, T x_{2 l+1}\right) \leq \frac{\lambda}{k} m\left(x_{2 l}, x_{2 l+1}\right)
$$

where

$$
\begin{aligned}
& m\left(x_{2 l}, x_{2 l+1}\right) \\
& \in k\left\{d\left(F x_{2 l}, G x_{2 l+1}\right), d\left(F x_{2 l}, S x_{2 l}\right)+d\left(G x_{2 l+1}, T x_{2 l+1}\right),\right. \\
&\left.d\left(F x_{2 l}, T x_{2 l+1}\right)+d\left(S x_{2 l}, G x_{2 l+1}\right)\right\} \\
&= k\left\{d\left(z_{2 l-1}, z_{2 l}\right), d\left(z_{2 l-1}, z_{2 l}\right)+d\left(z_{2 l}, z_{2 l+1}\right), d\left(z_{2 l-1}, z_{2 l+1}\right)\right\} .
\end{aligned}
$$

Thus we have the following three cases:

(i) $d\left(z_{2 l}, z_{2 l+1}\right) \leq \lambda d\left(z_{2 l-1}, z_{2 l}\right)$;

(ii) $d\left(z_{2 l}, z_{2 l+1}\right) \leq \lambda\left[d\left(z_{2 l-1}, z_{2 l}\right)+d\left(z_{2 l}, z_{2 l+1}\right)\right] \leq\left(\frac{\lambda}{1-\lambda}\right) d\left(z_{2 l-1}, z_{2 l}\right)$;

(iii) $d\left(z_{2 l}, z_{2 l+1}\right) \leq \lambda d\left(z_{2 l-1}, z_{2 l+1}\right) \leq \lambda k\left[d\left(z_{2 l-1}, z_{2 l}\right)+d\left(z_{2 l}, z_{2 l+1}\right)\right] \leq\left(\frac{\lambda k}{1-\lambda k}\right) d\left(z_{2 l-1}, z_{2 l}\right)$.

So, inequality (3.3) is satisfied in this case, too. Therefore, (3.3) is satisfied for all $n \in \mathbb{N}$, and by iterating we get

$$
d\left(z_{n+1}, z_{n}\right) \leq \alpha^{n} d\left(z_{1}, z_{0}\right) .
$$


Since $k \geq 1$, for $m>n$ we have

$$
\begin{aligned}
d\left(z_{n}, z_{m}\right) & \leq k d\left(z_{n}, z_{n+1}\right)+k^{2} d\left(z_{n+1}, z_{n+2}\right)+\cdots+K^{m-n-1} d\left(z_{m-1}, z_{m}\right) \\
& \leq\left(k \alpha^{n}+k^{2} \alpha^{n+1}+\cdots+K^{m-n-1} \alpha^{m-1}\right) d\left(z_{1}, z_{0}\right) \\
& \leq\left(\frac{k}{1-k \alpha}\right) \alpha^{n} d\left(z_{1}, z_{0}\right) \rightarrow 0 \quad \text { as } n \rightarrow \infty .
\end{aligned}
$$

Now, by $\left(C_{4}\right)$ and $\left(C_{1}\right)$, it follows that for every $c \in \operatorname{int} P$ there exists a positive integer $n_{0}$ such that $d\left(z_{n}, z_{m}\right) \ll c$ for every $m>n>n_{0}$, so $\left\{z_{n}\right\}$ is a Cauchy sequence.

Let us suppose that $S X$ is a complete subspace of $X$, then there exists $z \in S X$ such that $\lim _{n \rightarrow \infty} z_{2 n}=\lim _{n \rightarrow \infty} S x_{2 n}=z$. Then we have

$$
\lim _{n \rightarrow \infty} G x_{2 n+1}=\lim _{n \rightarrow \infty} S x_{2 n}=\lim _{n \rightarrow \infty} F x_{2 n}=\lim _{n \rightarrow \infty} T x_{2 n+1}=z,
$$

that is, for any $0 \ll c$, for sufficient large $n$, we have $d\left(z_{n}, z\right) \ll c$. Since $z \in S X \subset G X$, then there exists $y \in X$ such that $z=G y$. Let us prove that $z=T y$. From $\left(\mathrm{d}_{3}\right)$ and (3.2), we get

$$
\begin{aligned}
d(T y, z) & \leq k\left[d\left(T y, S x_{2 n}\right)+d\left(S x_{2 n}, z\right)\right] \\
& \leq \lambda m\left(x_{2 n}, y\right)+k d\left(z_{2 n}, z\right),
\end{aligned}
$$

where

$$
\begin{aligned}
m\left(x_{2 n}, y\right) & \in k\left[d\left(F x_{2 n}, G y\right), d\left(F x_{2 n}, S x_{2 n}\right)+d(G y, T y), d\left(F x_{2 n}, T y\right)+d\left(S x_{2 n}, G y\right)\right] \\
& =k\left[d\left(z_{2 n-1}, z\right), d\left(z_{2 n-1}, z_{2 n}\right)+d(z, T y), d\left(z_{2 n-1}, T y\right)+d\left(z_{2 n}, z\right)\right] .
\end{aligned}
$$

Therefore we have three cases:

(i) $d(T y, z) \leq k \lambda d\left(z_{2 n-1}, z\right)+k d\left(z_{2 n}, z\right) \ll k \lambda \frac{c}{2 k \lambda}+k \frac{c}{2 k}=c$ as $n \rightarrow \infty$;

(ii) $d(T y, z) \leq k \lambda\left[d\left(z_{2 n-1}, z_{2 n}\right)+d(z, T y)\right]+k d\left(z_{2 n}, z\right) \ll \frac{k}{1-\lambda k}\left[\lambda \frac{1-\lambda k}{2 k \lambda} c+\frac{1-\lambda k}{2 k} c\right]=c$ as $n \rightarrow \infty$ (since $1 \leq k \leq 2$ and $\lambda \in\left(0, \frac{1}{k+k^{2}}\right)$, we have $\lambda<\frac{1}{k}$, and therefore $1-\lambda k>0$ );

(iii)

$$
\begin{aligned}
d(T y, z) & \leq \lambda k\left[d\left(z_{2 n-1}, T y\right)+d\left(z_{2 n}, z\right)\right]+k d\left(z_{2 n}, z\right) \\
& \leq \lambda k\left[k\left\{d\left(z_{2 n-1}, z\right)+d(z, T y)\right\}+d\left(z_{2 n}, z\right)\right]+k d\left(z_{2 n}, z\right) \\
& \leq \frac{k}{1-\lambda k^{2}}\left[\lambda k d\left(z_{2 n-1}, z\right)+\lambda d\left(z_{2 n}, z\right)+d\left(z_{2 n}, z\right)\right] \\
& \ll \frac{k}{1-\lambda k^{2}}\left[\lambda k \frac{1-\lambda k^{2}}{4 \lambda k^{2}} c+\lambda \frac{1-\lambda k^{2}}{4 \lambda k} c+\frac{1-\lambda k^{2}}{2 k}\right]=c \quad \text { as } n \rightarrow \infty
\end{aligned}
$$

(since $k \geq 1$ and $\lambda \in\left(0, \frac{1}{k+k^{2}}\right)$, we have $\lambda<\frac{1}{k+k^{2}}<\frac{1}{k^{2}}$, and therefore $1-\lambda k^{2}>0$ ). Therefore, $d(T y, z) \ll c$ for each $c \in \operatorname{int} P$. So, by $\left(\mathrm{C}_{2}\right)$ we have $d(T y, z)=0$, that is,

$$
T y=G y=z
$$

so, $z$ is a point of coincidence of $T$ and $G$. 
Since $T X \subset F X$, there exists $v \in X$ such that $z=F v$. From $\left(\mathrm{d}_{3}\right)$ and (3.2), we have

$$
d(S v, z) \leq k\left[d\left(S v, T x_{2 n+1}\right)+d\left(T x_{2 n+1}, z\right)\right] \leq \lambda m\left(v, x_{2 n+1}\right)+k d\left(z_{2 n+1}, z\right)
$$

where

$$
\begin{aligned}
m\left(v, x_{2 n+1}\right) \in & k\left\{d\left(F v, G x_{2 n+1}\right), d(F v, S v)+d\left(G x_{2 n+1}, T x_{2 n+1}\right)\right. \\
& \left.d\left(F v, T x_{2 n+1}\right)+d\left(S v, G x_{2 n+1}\right)\right\} \\
= & k\left\{d\left(z, z_{2 n}\right), d(z, S v)+d\left(z_{2 n}, z_{2 n+1}\right), d\left(z, z_{2 n+1}\right)+d\left(S v, z_{2 n}\right)\right\} .
\end{aligned}
$$

Therefore we have the following three cases:

(i) $d(S v, z) \leq \lambda k d\left(z, z_{2 n}\right)+k d\left(z_{2 n+1}, z\right)$;

(ii) $d(S v, z) \leq \lambda k\left[d(z, S v)+d\left(z_{2 n}, z_{2 n+1}\right)\right]+k d\left(z_{2 n+1}, z\right)$;

(iii) $d(S v, z) \leq \lambda k\left[d\left(z, z_{2 n+1}\right)+d\left(S v, z_{2 n}\right)\right]+k d\left(z_{2 n+1}, z\right)$.

By the same argument as above, we get $d(S v, z)=0$, that is, $S v=F v=z$. So, $z$ is also a point of coincidence of $S$ and $F$.

Theorem 3.4 In addition to the hypothesis of Theorem 3.3, suppose that $\{S, F\}$ and $\{T, G\}$ are weakly compatible pairs, then $F, G, S$, and T have a common fixed point.

Proof From Theorem 3.3, we get that the mappings $\{S, F\}$ and $\{T, G\}$ have a point of coincidence in $z \in X$. Now we prove that $z$ is a unique point of coincidence of pairs $\{S, F\}$ and $\{T, G\}$. Suppose that there exists $z^{*} \in X$ such that $F v^{*}=G y^{*}=S v^{*}=T y^{*}=z^{*}$, from (3.2),

$$
d\left(z, z^{*}\right)=d\left(S v, T y^{*}\right) \leq \frac{\lambda}{k} m\left(v, y^{*}\right)
$$

where

$$
\begin{aligned}
m\left(v, y^{*}\right) & \in k\left\{d\left(F v, G y^{*}\right), d(F v, S v)+d\left(G y^{*}, T y^{*}\right), d\left(F v, T y^{*}\right)+d\left(S v, G y^{*}\right)\right\} \\
& =k\left\{d\left(z, z^{*}\right), d\left(z, z^{*}\right)+d\left(z, z^{*}\right)\right\}=k\left\{d\left(z, z^{*}\right), 2 d\left(z, z^{*}\right)\right\} .
\end{aligned}
$$

Using $\left(\mathrm{C}_{3}\right)$, we get $d\left(z, z^{*}\right)=0$, that is, $z=z^{*}$. Therefore, $z$ is a unique point of coincidence of the pairs $\{S, F\}$ and $\{T, G\}$. That is, $S v=F v=T y=G y=z$.

The weak compatibility of the pair $\{S, F\}$ implies $S F v=F S v=S S v=F F v=S z=F z$.

Now we show that $z$ is a common fixed point of $S$ and $F$.

Consider

$$
d(S z, z)=d(S z, T y) \leq \frac{\lambda}{k} m(z, y),
$$

where

$$
\begin{aligned}
m(z, y) & \in k\{d(F z, G y), d(F z, S z)+d(G y, T y), d(F z, T y)+d(S z, G y)\} \\
& =k\{d(S z, z), d(S z, z)+d(S z, z)\} \\
& =k\{d(S z, z), 2 d(S z, z)\} .
\end{aligned}
$$


Using $\left(C_{3}\right)$, we get $S z=z=F z$. Similarly, the weak compatibility of the pair $\{T, G\}$ implies $T z=z=G z$. Hence $S z=F z=T z=G z=z$.

Remark 3.5 Theorem 3.4 is a generalization of Theorem 3.1 of [14].

If we choose $T=S$ and $G=F$ in Theorems 3.3 and 3.4, we get the following results for two mappings on a cone metric type space.

Corollary 3.6 Let $(X, d)$ be a cone metric type space with the constant $k \geq 1$ and let $P$ be a solid cone. Suppose that the self-mappings $F, S: X \rightarrow X$ are such that $S X \subset F X$. Let $x_{0} \in X$, let the sequences $\left\{x_{n}\right\}$ and $\left\{z_{n}\right\}$ be defined by $z_{2 n}=F x_{2 n+1}=S x_{2 n}$ and $z_{2 n+1}=F x_{2 n+2}=S x_{2 n+1}$ for $n \geq 0$, and let $\mathcal{O}\left(x_{0}\right)=\left\{z_{n}: n \geq 0\right\}$. Assume that there exists $x_{0} \in X$ such that for some constant $\lambda \in\left(0, \frac{1}{k+k^{2}}\right)$,

$$
d(S x, S y) \leq \frac{\lambda}{k} m(x, y)
$$

where

$$
m(x, y) \in k\{d(F x, F y), d(F x, S x)+d(F y, S y), d(F x, S y)+d(S x, F y)\}
$$

for all $x, y \in F^{-1}\left\{\overline{\mathcal{O}\left(x_{0}\right)}\right\} \cup S^{-1}\left\{\overline{\mathcal{O}\left(x_{0}\right)}\right\}$. If one of $S X$ or $F X$ is a complete subspace of $X$, then $S$ and $F$ have a unique point of coincidence in $X$. Moreover, if $\{S, F\}$ is a weakly compatible pair, then $S$ and $F$ have a common fixed point.

The following example shows that Theorem 3.4 is different from Theorem 3.1 of Cvetković et al. [14].

Example 3.7 Let $X=\{0,1,2\}$, and let $d(x, y)=|x-y|$ for each $x, y \in X$. Let $T: X \rightarrow X$ be given by $T 0=2, T 2=2$ and $T 1=1$. Let $S=T$ and let $F=G=I$. We first show that we cannot invoke Theorem 3.1 of [14] to show the existence of a fixed point for $T$. On the contrary, assume that there exists $\lambda \in(0,1)$ such that

$$
|T x-T y| \leq \lambda \max \left\{|x-y|,|x-T x|,|y-T y|, \frac{|x-T y|+|y-T x|}{2}\right\}
$$

for each $x, y \in X$. Let $x=1$ and $y=2$. Then, from the above, we get $1 \leq \lambda$, a contradiction.

Now let $x_{0}=0$. Then $\mathcal{O}\left(x_{0}\right)=\{0,2\}$ and so $F^{-1}\left\{\overline{\mathcal{O}\left(x_{0}\right)}\right\} \cup G^{-1}\left\{\overline{\mathcal{O}\left(x_{0}\right)}\right\}=\{0,2\}$. Since for each $x, y \in\{0,2\}, T x=T y$, then the assumptions of Theorem 3.4 are satisfied by any $\lambda \in$ $\left(0, \frac{1}{2}\right)$. Thus $T$ has a fixed point.

\section{Generalized nonexpansive maps}

The aim of this section is to present coincidence points results for four mappings without satisfying the condition of continuity and commutation on cone metric type spaces with a non-normal cone. Common fixed point theorems are obtained under the weak compatible condition. Our results generalize and unify main results in $[40,43]$ and many others.

First, we give some common fixed point theorems for generalized nonexpansive mappings defined on a cone metric type space. 
Theorem 4.1 Let $(X, d)$ be a cone metric type space with the constant $k \geq 1$ and let $P$ be a solid cone. Suppose that the mappings $F, G, S, T: X \rightarrow X$ are such that $S X \subset G X, T X \subset F X$ satisfying

$$
d(S x, T y) \leq a d(F x, G y)+b\{d(F x, S x)+d(G y, T y)\}+c\{d(F x, T y)+d(G y, S x)\}
$$

for all $x, y \in X$, where $a, b$ and $c(\neq 0)$ are nonnegative constants such that $b+(a+b+$ $c) k+c k^{2}<1$. If one of $S X, T X, F X$, or GX is a complete subspace of $X$, then $\{S, F\}$ and $\{T, G\}$ have a unique point of coincidence in $X$. Moreover, if $\{S, F\}$ and $\{T, G\}$ are weakly compatible pairs, then $F, G, S$, and T have a unique common fixed point.

Proof We define sequences $\left\{x_{n}\right\}$ and $\left\{z_{n}\right\}$ as in the proof of Theorem 3.3. We prove that $\left\{z_{n}\right\}$ is a Cauchy sequence by considering the cases when $n$ is odd and even, respectively.

For $n=2 l+1, l \in \mathbb{N}$, we have

$$
\begin{aligned}
d\left(z_{2 l+1}, z_{2 l+2}\right)= & d\left(S x_{2 l+2}, T x_{2 l+1}\right) \\
\leq & a d\left(F x_{2 l+2}, G x_{2 l+1}\right)+b\left\{d\left(F x_{2 l+2}, S x_{2 l+2}\right)+d\left(G x_{2 l+1}, T x_{2 l+1}\right)\right\} \\
& +c\left\{d\left(F x_{2 l+2}, T x_{2 l+1}\right)+d\left(G x_{2 l+1}, S x_{2 l+2}\right)\right\} \\
= & a d\left(z_{2 l+1}, z_{2 n}\right)+b\left\{d\left(z_{2 l+1}, z_{2 l+2}\right)+d\left(z_{2 l}, z_{2 l+1}\right)\right\} \\
& +c\left\{d\left(z_{2 l+1}, z_{2 l+1}\right)+d\left(z_{2 l}, z_{2 l+2}\right)\right\} \\
= & (a+b) d\left(z_{2 l+1}, z_{2 n}\right)+c d\left(z_{2 l}, z_{2 l+2}\right)+b d\left(z_{2 l+1}, z_{2 l+2}\right) \\
\leq & (a+b) d\left(z_{2 l+1}, z_{2 n}\right)+c k\left[d\left(z_{2 l}, z_{2 l+1}\right)+d\left(z_{2 l+1}, z_{2 l+2}\right)\right]+b d\left(z_{2 l+1}, z_{2 l+2}\right) \\
= & (a+b+k c) d\left(z_{2 l+1}, z_{2 n}\right)+(b+c k) d\left(z_{2 l+1}, z_{2 l+2}\right) .
\end{aligned}
$$

Therefore

$$
d\left(z_{2 l+1}, z_{2 l+2}\right) \leq\left(\frac{a+b+c k}{1-b-c k}\right) d\left(z_{2 l+1}, z_{2 n}\right) .
$$

Similarly, for $n=2 l, l \in \mathbb{N}$, we have

$$
\begin{aligned}
d\left(z_{2 l}, z_{2 l+1}\right)= & d\left(S x_{2 l}, T x_{2 l+1}\right) \\
\leq & a d\left(F x_{2 l}, G x_{2 l+1}\right)+b\left\{d\left(F x_{2 l}, S x_{2 l}\right)+d\left(G x_{2 l+1}, T x_{2 l+1}\right)\right\} \\
& +c\left\{d\left(F x_{2 l}, T x_{2 l+1}\right)+d\left(G x_{2 l+1}, S x_{2 l}\right)\right\} \\
= & a d\left(z_{2 l-1}, z_{2 n}\right)+b\left\{d\left(z_{2 l-1}, z_{2 l}\right)+d\left(z_{2 l}, z_{2 l+1}\right)\right\} \\
& +c\left\{d\left(z_{2 l-1}, z_{2 l+1}\right)+d\left(z_{2 l}, z_{2 l}\right)\right\} \\
= & (a+b) d\left(z_{2 l-1}, z_{2 n}\right)+b d\left(z_{2 l}, z_{2 l+1}\right)+c d\left(z_{2 l-1}, z_{2 l+1}\right) \\
\leq & (a+b) d\left(z_{2 l-1}, z_{2 n}\right)+b d\left(z_{2 l}, z_{2 l+1}\right) \\
& +c k\left[d\left(z_{2 l-1}, z_{2 n}\right)+d\left(z_{2 l}, z_{2 l+1}\right)\right] .
\end{aligned}
$$


Thus,

$$
d\left(z_{2 l}, z_{2 l+1}\right) \leq\left(\frac{a+b+c k}{1-b-c k}\right) d\left(z_{2 l-1}, z_{2 n}\right) .
$$

Let $\alpha=\frac{a+b+c k}{1-b-c k}$. Clearly $\alpha<1$. Hence, inequality (4.2) holds for both the cases. By the same arguments as in Theorem 3.3, we conclude that $\left\{z_{n}\right\}$ is a Cauchy sequence. Let us suppose that $S X$ is a complete subspace of $X$, then there exists $z \in S X$ such that $\lim _{n \rightarrow \infty} z_{2 n}=\lim _{n \rightarrow \infty} S x_{2 n}=z$. Then we have

$$
\lim _{n \rightarrow \infty} G x_{2 n+1}=\lim _{n \rightarrow \infty} S x_{2 n}=\lim _{n \rightarrow \infty} F x_{2 n}=\lim _{n \rightarrow \infty} T x_{2 n+1}=z,
$$

that is, for any $0 \ll c$, for sufficient large $n$, we have $d\left(z_{n}, z\right) \ll c$. Since $z \in S X \subset G X$, then there exists $y \in X$ such that $z=G y$. We prove that $z=T y$. From $\left(\mathrm{d}_{3}\right)$ and (4.1), we have

$$
\begin{aligned}
d(T y, z) \leq & k\left[d\left(S x_{2 n}, T y\right)+d\left(S x_{2 n}, z\right)\right] \\
\leq & k\left[a d\left(F x_{2 n}, G y\right)+b\left\{d\left(F x_{2 n}, S x_{2 n}\right)+d(G y, T y)\right\}\right. \\
& \left.+c\left\{d\left(F x_{2 n}, T y\right)+d\left(G y, S x_{2 n}\right)\right\}\right]+k d\left(S x_{2 n}, z\right) \\
= & k\left[a d\left(z_{2 n-1}, z\right)+b\left\{d\left(z_{2 n-1}, z_{2 n}\right)+d(z, T y)\right\}\right. \\
& \left.+c\left\{d\left(z_{2 n-1}, T y\right)+d\left(z, z_{2 n}\right)\right\}\right]+k d\left(z_{2 n}, z\right) \\
\leq & k\left[a d\left(z_{2 n-1}, z\right)+b\left\{d\left(z_{2 n-1}, z_{2 n}\right)+d(z, T y)\right\}\right. \\
& \left.+c\left\{k\left[d\left(z_{2 n-1}, z\right)+d(z, T y)\right]+d\left(z, z_{2 n}\right)\right\}\right]+k d\left(z_{2 n}, z\right) \\
= & k\left[(a+k c) d\left(z_{2 n-1}, z\right)+(c+1) d\left(z, z_{2 n}\right)+(b+c k) d(z, T y)+b d\left(z_{2 n-1}, z_{2 n}\right)\right] .
\end{aligned}
$$

Since $\left\{z_{n}\right\}$ converges to $z$, so for each $t \in \operatorname{int} P$, there exists $n_{0} \in \mathbb{N}$ such that for every $n>n_{0}$,

$$
\begin{aligned}
d(T y, z) \leq & \left(\frac{k}{1-b k-c k^{2}}\right)\left[(a+k c) d\left(z_{2 n-1}, z\right)+(c+1) d\left(z, z_{2 n}\right)+b d\left(z_{2 n-1}, z_{2 n}\right)\right] \\
\ll & \left(\frac{k}{1-b k-c k^{2}}\right)\left[\frac{(a+k c) t}{3} \frac{\left(1-b k-c k^{2}\right)}{k(a+k c)}\right. \\
& \left.+\frac{(c+1) t}{3} \frac{\left(1-b k-c k^{2}\right)}{k(c+1)}+\frac{b t}{3} \frac{\left(1-b k-c k^{2}\right)}{b k}\right] \\
= & t .
\end{aligned}
$$

Now, by $\left(\mathrm{C}_{2}\right)$ it follows that $d(z, T y)=0$, that is, $T y=z$. So, we have $T y=G y=z$, that is, $z$ is a point of coincidence of $T$ and $G$.

Since $T X \subset F X$, there exists $u \in X$ such that $z=F u$. From $\left(\mathrm{d}_{3}\right)$ and (4.1), we have

$$
\begin{aligned}
d(S u, z) \leq & k\left[d\left(S u, T x_{2 n+1}\right)+d\left(T x_{2 n+1}, z\right)\right] \\
\leq & k\left[a d\left(F u, G x_{2 n+1}\right)+b\left\{d(F u, S u)+d\left(G x_{2 n+1}, T x_{2 n+1}\right)\right\}\right. \\
& \left.+c\left\{d\left(F u, T x_{2 n+1}\right)+d\left(G x_{2 n+1}, S u\right)\right\}+d\left(T x_{2 n+1}, z\right)\right] \\
= & k\left[a d\left(z, z_{2 n}\right)+b\left\{d(z, S u)+d\left(z_{2 n}, z_{2 n+1}\right)\right\}\right.
\end{aligned}
$$




$$
\begin{aligned}
& \left.+c\left\{d\left(z, z_{2 n+1}\right)+d\left(z_{2 n}, S u\right)\right\}+d\left(z_{2 n+1}, z\right)\right] \\
\leq & k\left[a d\left(z, z_{2 n}\right)+b\left\{d(z, S u)+d\left(z_{2 n}, z_{2 n+1}\right)\right\}\right. \\
& \left.+c\left\{d\left(z, z_{2 n+1}\right)+k\left[d\left(z_{2 n}, z\right)+d(z, S u)\right]\right\}+d\left(z_{2 n+1}, z\right)\right],
\end{aligned}
$$

so by the same arguments as above, we have $d(S u, z)=0$, that is, $S u=F u=T y=G y=z$.

Suppose that $z^{*}$ is another point of coincidence of these four mappings, that is, $F u^{*}=$ $S u^{*}=G y^{*}=T y^{*}=z^{*}$. From (4.1) we get

$$
\begin{aligned}
d\left(z, z^{*}\right) & =d\left(S u, T y^{*}\right) \\
& \leq a d\left(F u, G y^{*}\right)+b\left\{d(F u, S u)+d\left(G y^{*}, T y^{*}\right)\right\}+c\left\{d\left(F u, T y^{*}\right)+d\left(G y^{*}, S u\right)\right\} \\
& \leq(a+2 c k) d\left(z, z^{*}\right),
\end{aligned}
$$

because of $\left(\mathrm{C}_{3}\right)$, we get $z=z^{*}$. Therefore, $z$ is the unique point of coincidence of $S, F, G$ and $T$. The weak compatibility of the pair $\{S, F\}$ implies $S F u=F S u=S S u=F F u=S z=F z$, and the weak compatibility of the pair $\{T, G\}$ gives $G T y=T G y=G G y=T T y=G z=T z$. Consider

$$
\begin{aligned}
d(z, S z) & =d(T y, S z) \\
& \leq a d(F z, G y)+b\{d(F z, S z)+d(G y, T y)\}+c\{d(F z, T y)+d(G y, S z)\} \\
& =(a+2 c) d(S z, z) .
\end{aligned}
$$

Since $b+(a+b+c) k+c k^{2}<1$ and using $\left(C_{3}\right)$, we get $S z=F z=z$; similarly we have $T z=$ $G z=z$. This shows that $z$ is a common fixed point of $G, T, F$ and $S$. The proof for the cases in which $F X$ or $G X$ or $T X$ is complete are similar. Hence the theorem follows.

Choosing $k=1$ in Theorem 4.1, we obtain the following generalized form of the results in [40] and [43].

Corollary 4.2 Let $(X, d)$ be a cone metric space and $P$ be a solid cone. Suppose that the mappings $F, G, S, T: X \rightarrow X$ are such that $S X \subset G X, T X \subset F X$ and that there exist nonnegative constants $a, b$ andc satisfying

$$
a+2 b+2 c<1
$$

such that for all $x, y \in X$,

$$
d(S x, T y) \leq a d(F x, G y)+b\{d(F x, S x)+d(G y, T y)\}+c\{d(F x, T y)+d(G y, S x)\} .
$$

Ifone of $S X, T X, F X$, or $G X$ is a complete subspace of $X$, then $\{S, F\}$ and $\{T, G\}$ have a unique point of coincidence in $X$. Moreover, if $\{S, F\}$ and $\{T, G\}$ are weakly compatible pairs, then $F, G, S$, and $T$ have a unique common fixed point.

If we choose $T=S$ and $G=F$ in Theorem 4.1, we get the following result for two mappings on a cone metric type space. 
Corollary 4.3 Let $(X, d)$ be a cone metric type space with the constant $k \geq 1$ and let $P$ be a solid cone. Suppose that the mappings $G, T: X \rightarrow X$ are such that $T X \subset G X$ and that there exist nonnegative constants $a, b$ andc, satisfying $b+(a+b+c) k+c k^{2}<1$, such that for all $x, y \in X$,

$$
d(S x, T y) \leq a d(G x, G y)+b\{d(G x, T x)+d(G y, T y)\}+c\{d(G x, T y)+d(G y, T x)\} .
$$

If one of $T X$ or $G X$ is a complete subspace of $X$, then $G$ and $T$ have a unique point of coincidence in $X$. Moreover, if $\{T, G\}$ is a weakly compatible pair, then $G$ and $T$ have a unique common fixed point.

Now, we use the following lemma, that is a consequence of the axiom of choice, to obtain coincidence point results for two self-mappings defined on a subset of a partially ordered cone metric type space (see $[45,46])$.

Lemma 4.4 Let $X$ be a nonempty set and let $g: X \rightarrow X$ be a mapping. Then there exists a subset $E \subseteq X$ such that $g(E)=g(X)$ and $g: E \rightarrow X$ is one-to-one.

The following result contains properly the recent main result (Theorem 2.1) of Shi and $\mathrm{Xu}$ [39]. Here we shall establish this result in the set up of a partially ordered cone metric type space relative to a solid cone $P$.

Theorem 4.5 (Theorem 2.10 of [38]) Let $(X, d)$ be a cone metric type space with the constant $k \geq 1$ and let $P$ be a cone having a nonempty interior. Suppose that the mappings $f, g: X \rightarrow X$ are such that $f X \subseteq g X$ and $f X$ or $g X$ is a complete subspace of $X$ and that there exist nonnegative constants $a_{1}, a_{2}, a_{3}, a_{4}, a_{5} \in[0,1)$ with $2 k a_{1}+(k+1)\left(a_{2}+a_{3}\right)+\left(k^{2}+k\right)\left(a_{4}+\right.$ $\left.a_{5}\right)<2$ such that, for each $x, y \in X$,

$$
d(f x, f y) \leq a_{1} d(g x, g y)+a_{2} d(g x, f x)+a_{3} d(g y, f y)+a_{4} d(g x, f y)+a_{5} d(g y, f x) .
$$

Then $f$ and $g$ have a unique point of coincidence in X. Moreover, iff and $g$ are OWC, $f$ and $g$ have a unique common fixed point.

Recall that if $(X, \preceq)$ is a partially ordered set and $f, g: X \rightarrow X$ is such that for $x, y \in X$, $x \preceq y$ implies $f x \preceq f y$, then the mapping $f$ is said to be nondecreasing. Further, for $x, y \in X$, $g x \preceq g y$ implies $f x \preceq f y$, then the mapping $f$ is said to be $g$-nondecreasing [34].

The following result extends Theorem 4.5 and corresponding results in Altun et al. [5, 6] and many others (see also Lemma 2.3 [34]).

Theorem 4.6 Let $(X, d, \preceq)$ be a partially ordered cone metric type space relative to a solid cone $P$ with the constant $k \geq 1$. Suppose that the mappings $f, g: X \rightarrow X$ are such that $f$ is g-nondecreasing mapping w.r.t. $\preceq, ~ f X \subseteq g X$ and $g X$ is a complete subspace of $X$. Suppose that the following assertions hold:

(a) $f$ is continuous or $X$ has the following property: if a nondecreasing sequence $\left\{g x_{n}\right\} \rightarrow g x$, then $g x_{n} \preceq g x$ for all $n \geq 0$;

(b) there exist nonnegative constants $a_{1}, a_{2}, a_{3}, a_{4}, a_{5} \in[0,1)$ with $2 k a_{1}+(k+1)\left(a_{2}+a_{3}\right)+\left(k^{2}+k\right)\left(a_{4}+a_{5}\right)<2 ;$ 
(c) for each $x, y \in X$ with $g y \preceq g x$, we have

$$
\begin{aligned}
d(f x, f y) \leq & a_{1} d(g x, g y)+a_{2} d(g x, f x)+a_{3} d(g y, f y) \\
& +a_{4} d(g x, f y)+a_{5} d(g y, f x) .
\end{aligned}
$$

If there exists $x_{0} \in X$ such that $g\left(x_{0}\right) \preceq f\left(x_{0}\right)$, then $f$ and $g$ have a coincidence point in $X$.

Proof Using Lemma 4.4, there exists $E \subseteq X$ such that $g(E)=g(X)$ and $g: E \rightarrow X$ is one-toone. We define a mapping $G: g(E) \rightarrow g(E)$ by

$$
G(g x)=f(x)
$$

for all $g x \in g(E)$. As $g$ is one-to-one on $g(E)=g(X)$ and $f(X) \subseteq g(X)$, so $G$ is well defined. Thus, it follows from (4.4) and (4.5) that

$$
d(G g x, G g y)=d(f x, f y) \leq a_{1} d(g x, g y)+a_{2} d(g x, f x)+a_{3} d(g y, f y)+a_{4} d(g x, f y)+a_{5} d(g y, f x)
$$

for all $g x, g y \in g(X)$ for which $g(y) \preceq g(x)$. Since $f$ is a $g$-nondecreasing mapping, for all $g y \preceq g x \in g(X)$, it implies $f y \preceq f x$, which gives $G g y \preceq G g x$. Thus $G$ is a nondecreasing mapping on $g(X)$. Also, there exists $x_{0} \in X$ such that $g\left(x_{0}\right) \preceq f\left(x_{0}\right)=G\left(g x_{0}\right)$. Suppose that the assumption (a) holds. Since $f$ is continuous, $G$ is also continuous. Using Theorem 2.2 [4] to the mapping $G$, it follows that $G$ has a fixed point $u \in g(X)$.

Suppose that the assumption (b) holds. We conclude similarly from Theorem 2.3 [4] that the mapping $G$ has a fixed point $u \in g(X)$. Finally, we prove that $f$ and $g$ have a coincidence point. Since $u$ is a fixed point of $G$, we get $u=G u$. Since $u \in g(X)$, there exists a point $u_{0} \in X$ such that $u=g u_{0}$. It follows that $g u_{0}=u=G u=G g u_{0}=f u_{0}$. Thus, $u_{0}$ is a required coincidence point of $f$ and $g$. This completes the proof.

\section{Application to the existence of solutions of integral equations}

Fixed point theorems for operators in ordered Banach spaces are widely investigated and have found various applications in differential and integral equations (see $[1,24]$ and references therein). Let $X=C([0 ; T] ; \mathbb{R})$ be the set of real continuous functions defined on $[0 ; T]$ and let $d: X \times X \rightarrow[0 ;+\infty)$ be defined by $d(x, y)=\sup _{t \in[0, T]}|x(t)-y(t)|^{2}$. Then $(X, d)$ is a complete metric type space with the constant $k=2$.

Consider the integral equation

$$
F u(t)=p(t)+\int_{0}^{T} G(t, s) f(s, u(s)) d s,
$$

and let $S: X \rightarrow X$ be defined by

$$
(S u)(t)=p(t)+\int_{0}^{T} G(t, s) f(s, u(s)) d s \quad \text { for each } t \in[0, T] .
$$

We assume that

(i) $p:[0, T] \rightarrow \mathbb{R}$ is continuous;

(ii) $G(t, s):[0, T] \times[0, T] \rightarrow \mathbb{R}$ is continuous; 
(iii) $|f(s, u(s))-f(s, v(s))| \leq \mu \max \{|F u(s)-F v(s)|,|F u(s)-S u(s)|+|F v(s)-S v(s)|$, $|F u(s)-S v(s)|+|S u(s)-F v(s)|\}$ for each $u, v \in X$ and $s \in[0, T]$, where $\mu$ is a constant such that $2 T \mu^{2} \sup _{t \in[0, T]} \int_{0}^{T}|G(t, s)|^{2} d s<\frac{1}{4}$.

Theorem 5.1 Under the assumptions (i)-(iii), the integral equation (5.1) has a solution in $X=C([0 ; T] ; \mathbb{R})$.

Proof Consider the mapping $S: X \rightarrow X$ defined by (5.2). Notice first that the existence of a solution for the integral equation (5.1) is equivalent to the existence of a common fixed point for the mappings $F$ and $S$. For each $u, v \in X$, we have

$$
\begin{aligned}
d(S u, S v)= & \sup _{t \in[0, T]}|S u(t)-S v(t)|^{2} \\
\leq & \sup _{t \in[0, T]}\left\{\int_{0}^{T}|G(t, s)| f(s, u(s))-f(s, v(s)) \mid d s\right\}^{2} \\
\leq & \sup _{t \in[0, T]} \int_{0}^{T}|G(t, s)|^{2} d s \int_{0}^{T}|f(s, u(s))-f(s, v(s))|^{2} d s \\
\leq & 2 \mu^{2} \sup _{t \in[0, T]} \int_{0}^{T}|G(t, s)|^{2} d s \\
& \times \int_{0}^{T} \max _{0}\left\{|F u(s)-F v(s)|^{2},|F u(s)-S u(s)|^{2}+|F v(s)-S v(s)|^{2},\right. \\
& \left.|F u(s)-S v(s)|^{2}+|S u(s)-F v(s)|^{2}\right\} d s \\
\leq & 2 T \mu^{2} \sup _{t \in[0, T]} \int_{0}^{T}|G(t, s)|^{2} d s \\
& \times \max \{d(F u, F v), d(F u, S u)+d(F v, S v), d(F u, S v)+d(S u, F v)\} .
\end{aligned}
$$

Hence all the hypotheses of Corollary 3.6 are satisfied, and so the mappings $F$ and $S$ have a common fixed point that is a solution in $X=C([0 ; T] ; \mathbb{R})$ of the integral equation (5.1).

Competing interests

The authors declare that they have no competing interests.

Authors' contributions

All authors contributed equally and significantly in writing this article. All authors read and approved the final manuscript.

\section{Author details}

'Department of Mathematics, King Abdul Aziz University, P.O. Box 80203, Jeddah, 21589, Saudi Arabia. ${ }^{2}$ Department of Mathematics, Lahore University of Management Sciences, Lahore, 54792, Pakistan. ${ }^{3}$ Department of Mathematics, University of Shahrekord, Shahrekord, 88186-34141, Iran. ${ }^{4}$ Department of Mathematics, The Islamia University of Bahawalpur, Bahawalpur, 63100, Pakistan.

\section{Acknowledgements}

The authors would like to express their thanks to the referees for their helpful comments and suggestions. The first author gratefully acknowledges the support from the Deanship of Scientific Research (DSR) at King Abdulaziz University (KAU) during this research. The third author was partially supported by the Center of Excellence for Mathematics, University of Shahrekord, Iran. 


\section{References}

1. Agarwal, RP, Hussain, N, Taoudi, M-A: Fixed point theorems in ordered Banach spaces and applications to nonlinear integral equations. Abstr. Appl. Anal. 2012, Article ID 245872 (2012)

2. Abbas, M, Vetro, P: Invariant approximation results in cone metric spaces. Ann. Funct. Anal. 2, 101-113 (2011)

3. Abbas, M, Vetro, P, Khan, SH: On fixed points of Berinde's contractive mappings in cone metric spaces. Carpath. J. Math. 26, 121-133 (2010)

4. Abusalim, SM, Md Noorani, MS: Fixed point and common fixed point theorems on ordered cone $b$-metric spaces. Abstr. Appl. Anal. 2013, Article ID 815289 (2013)

5. Altun, I, Durmaz, G: Some fixed point theorems on ordered cone metric spaces. Rend. Circ. Mat. Palermo 58, 319-325 (2009)

6. Altun, I, Damjanovic, B, Djoric, D: Fixed point and common fixed point theorems on ordered cone metric spaces. Appl. Math. Lett. 23, 310-316 (2010)

7. Arshad, M, Azam, A, Vetro, P: Common fixed point of generalized contractive type mappings in cone metric spaces. IAENG Int. J. Appl. Math. 41, 246-251 (2011)

8. Arshad, M, Azam, A, Vetro, P: Some common fixed results in cone metric spaces. Fixed Point Theory Appl. 2009, Article ID 493965 (2009)

9. Aydi, H, Samet, B, Vetro, C: Coupled fixed point results in cone metric spaces for $\widetilde{W}$-compatible mappings. Fixed Point Theory Appl. 2011, Article ID 27 (2011)

10. Choudhury, BS, Metiya, N: The point of coincidence and common fixed point for a pair of mappings in cone metric spaces. Comput. Math. Appl. 60(6), 1686-1695 (2010)

11. Ćirić, L: A generalization of Banach's contraction principle. Proc. Am. Math. Soc. 45, 267-273 (1974)

12. Ćirić, L, Hussain, N, Cakic, N: Common fixed points for Ciric type $f$-weak contraction with applications. Publ. Math. (Debr.) 76(1-2), 31-49 (2010)

13. Ćirić, L, Abbas, M, Saadati, R, Hussain, N: Common fixed points of almost generalized contractive mappings in ordered metric spaces. Appl. Math. Comput. 217, 5784-5789 (2011)

14. Cvetković, AS, Stanić, MP, Dimitrijević, S, Simić, S: Common fixed point theorems for four mappings on cone metric type space. Fixed Point Theory Appl. 2011, Article ID 589725 (2011)

15. Di Bari, C, Vetro, P: Common fixed points in cone metric spaces for MK-pairs and L-pairs. Ars Comb. 99, 429-437 (2011)

16. Di Bari, C, Saadati, R, Vetro, P: Common fixed points in cone metric spaces for CJM-pairs. Math. Comput. Model. 54, 2348-2354 (2011)

17. Di Bari, C, Vetro, P: Weakly $\varphi$-pairs and common fixed points in cone metric spaces. Rend. Circ. Mat. Palermo 58(1), 125-132 (2009)

18. Di Bari, C, Vetro, P: $\varphi$-pairs and common fixed points in cone metric spaces. Rend. Circ. Mat. Palermo 57(2), 279-285 (2008)

19. Huang, LG, Zhang, X: Cone metric spaces and fixed point theorems of contractive mappings. J. Math. Anal. Appl. 332(2), 1468-1476 (2007)

20. Hussain, N, Kadelburg, Z, Radenovic, S, Al-Solamy, FR: Comparison functions and fixed point results in partial metric spaces. Abstr. Appl. Anal. 2012, Article ID 605781 (2012)

21. Hussain, N, Dorić, D, Kadelburg, Z, Radenović, S: Suzuki-type fixed point results in metric type spaces. Fixed Point Theory Appl. 2012, Article ID 126 (2012)

22. Hussain, N, Shah, MH: KKM mappings in cone b-metric spaces. Comput. Math. Appl. 62, 1677-1684 (2011)

23. Hussain, N, Pathak, HK: Subweakly biased pairs and jungck contractions with applications. Numer. Funct. Anal. Optim. 32(10), 1067-1082 (2011)

24. Hussain, N, Khan, AR, Agarwal, RP: Krasnosel'skii and Ky Fan type fixed point theorems in ordered Banach spaces. J. Nonlinear Convex Anal. 11(3), 475-489 (2010)

25. Ilić, D, Rakočević, V: Quasi-contraction on cone metric spaces. Appl. Math. Lett. (2008). doi:10.1016/j.aml.2008.08.011

26. Janković, S, Golubović, Z, Radenović, S: Compatible and weakly compatible mappings in cone metric spaces. Math. Comput. Model. 52(9-10), 1728-1738 (2010)

27. Jungck, G, Radenović, S, Radojević, S, Rakočević, V: Common fixed point theorems for weakly compatible pairs on cone metric spaces. Fixed Point Theory Appl. 2009, Article ID 643840 (2009)

28. Jungck, G, Rhoades, BE: Fixed point theorems for occasionally weakly compatible mappings. Fixed Point Theory 7(2), 287-296 (2006)

29. Kadelburg, Z, Radenović, S, Rakočević, V: Remarks on quasi-contraction on a cone metric spaces. Appl. Math. Lett. 22 1674-1679 (2009)

30. Kadelburg, Z, Radenović, S, Rosić, B: Strict contractive conditions and common fixed point theorems on cone metric spaces. Fixed Point Theory Appl. 2009, Article ID 173838 (2009)

31. Khamsi, MA: Remarks on cone metric spaces and fixed point theorems of contractive mappings. Fixed Point Theory Appl. (2010). doi:10.1155/2010/315398

32. Khamsi, MA, Hussain, N: KKM mappings in metric type spaces. Nonlinear Anal. 73(9), 3123-3129 (2010)

33. Naimpally, SA, Sing, KL: Extensions of fixed point theorems of Rhoades. J. Math. Anal. Appl. 96, 437-446 (1983)

34. Parvaneh, $\mathrm{V}$, Roshan, JR, Radenović, S: Existence of tripled coincidence point in ordered b-metric spaces and application to a system of integral equations. Fixed Point Theory Appl. 2013, Article ID 130 (2013)

35. Radenović, S: Common fixed points under contractive conditions in cone metric spaces. Comput. Math. Appl. 58(6), 1273-1278 (2009)

36. Rahimi, H, Vetro, P, Rad, GS: Some common fixed point results for weakly compatible mappings in cone metric type space. Miskolc Math. Notes (in press)

37. Samet, B, Vetro, C: A fixed point theorem for uniformly locally contractive mappings in a c-chainable cone rectangular metric space. Surv. Math. Appl. 6, 107-116 (2011)

38. Shah, MH, Simic, S, Hussain, N, Sretenovic, A, Radenovic, S: Common fixed points theorems for occasionally weakly compatible pairs on cone metric type spaces. J. Comput. Anal. Appl. 14, 290-297 (2012)

39. Shi, L, Shaoyuan, $X$ : Common fixed point theorems for two weakly compatible self-mappings in cone $b$-metric spaces. Fixed Point Theory Appl. 2013, Article ID 120 (2013) 
40. Song, G, Sun, X, Zhao, Y, Wang, G: New common fixed point theorems for maps on cone metric spaces. Appl. Math. Lett. 23, 1033-1037 (2010)

41. Vetro, P: Common fixed points in cone metric spaces. Rend. Circ. Mat. Palermo 56, 464-468 (2007)

42. Vetro, P, Azam, A, Arshad, M: Fixed point results in cone metric spaces for contractions of Zamfirescu type. Indian J. Math. 52, 251-261 (2010)

43. Wang, S, Guo, B: Distance in cone metric spaces and common fixed point theorems. Appl. Math. Lett. 24, 1735-1739 (2011)

44. Zamfirescu, T: Fixed point theorems in metric spaces. Arch. Math. 23, 292-298 (1972)

45. Herman, R, Jean, ER: Equivalents of the Axiom of Choice. North-Holland, Amsterdam (1970)

46. Haghi, RH, Rezapour, S, Shahzad, N: Some fixed point generalizations are not real generalizations. Nonlinear Anal. 74, 1799-1803 (2011)

doi:10.1186/1687-1812-2013-169

Cite this article as: Hussain et al.: Common fixed point theorems for generalized contractive mappings with

applications. Fixed Point Theory and Applications 2013 2013:169.

Submit your manuscript to a SpringerOpen ${ }^{\circ}$ journal and benefit from:

- Convenient online submission

- Rigorous peer review

- Immediate publication on acceptance

- Open access: articles freely available online

- High visibility within the field

- Retaining the copyright to your article

Submit your next manuscript at $>$ springeropen.com 